\title{
Evaluation of a Service Intervention to Improve Uptake of Breast Cancer Screening in a London Borough with Many Hard to Reach Communities
}

\author{
Vincent Icheku $^{1, *}$, Nike Arowobusoye ${ }^{2}$ \\ ${ }^{1}$ School of health and social care, London South Bank University, UK \\ ${ }^{2}$ NHS Greenwich Public Health, UK
}

Copyright $@ 2015$ Horizon Research Publishing All rights reserved.

\begin{abstract}
Uptake of breast cancer screening is lowest in areas of London with many hard to reach communities. This report evaluates two interventions to improve uptake of breast cancer screening in the Royal London Borough of Greenwich with many hard to reach communities. The interventions involved splitting 2,004 women eligible for screening into two groups. Group 1 who were sent letter only invites has a target group $(n=1,452)$ and eligible women screened were $(n=878)$. Whilst, group 2 who were sent letter invites combined with Short Message service (SMS) reminder has a target group $(n=552)$ and eligible women screened were $(n=376)$. The result shows a significant difference in attendance rates between the two invitation methods. The screening uptake by the women who received invitation letter only had an attendance rate of 60 percent (table1). The screening uptake by the women who received invitation letter and SMS reminder was 68 percent (table 2). This amounts to 8 percent differential rate, which translates to an additional 44 women who were screened, as a direct result of receiving an SMS reminder. Applying the achieved result to the "Letter Only" group indicates that an additional 12 women would theoretically have been screened if the 'Letter only' invites were also sent with SMS reminder. An overall 2.54 percentage point increase in screening outcome was achieved when compared the uptake in the months of the project (July to Dec 2011) with the uptake in similar months in 2010. Finally, the results prove that intervention by letter invite combined with SMS reminder is the most effective method of improving uptake of breast cancer screening in the borough with many hard to reach communities.
\end{abstract}

Keywords Breast Cancer Screening, Hard-to-reach, Mammography, Short-Messaging-Service, SMS

\section{Introduction}

Breast cancer is a significant cause of mortality and morbidity amongst women and a major public health problem in the United Kingdom (UK). In 2010, breast cancer was by far the most common cancer among women in the UK, accounting for 31 percent of all new cases of cancer in women. [1] According Cancer Research UK, around 11,600 women died from breast cancer in 2012 and in UK; which is about 32 deaths every day. [2] However, over $80 \%$ of women with breast cancer are still alive five years after diagnosis. The survival rate for breast cancer was around 50 per cent 40 years ago. This means that more women than ever are surviving breast cancer mainly due to early detection through screening. [1]

The aim of Breast Screening Programme is to detect the disease at an early stage when there is a good chance of successful treatment. [3] Every woman registered with a GP in England should receive her first invitation before her 53rd birthday. [4] The National Health Service (NHS) Breast Screening Programme (NHSBSP) was established in March 1987 and began inviting women in 1988. The programme's purpose is to routinely invite women aged between 50 and 70 for screening by mammography. The NHS Breast Screening Programme saves an estimated 1,400 lives each year in England alone. [5] Regrettably, the uptake rates of breast cancer screening by eligible women have been on the decline in England despite all effort to increase uptake. In 2012-13, uptake was 72.2 per cent. This compares with 73.1 per cent in 2011-12 and 73.4 per cent in 2010-11. [4] London generally is characterised by low uptake of breast cancer screening. The percentage of uptake is around 64 percent, which is below national minimum standard of 70 percent. The low uptake in London is thought to be related to both socio-economic deprivation and ethnicity. [6] This view corroborates a report that London population is characterised by higher rates of mobility, ethnic diversity, young people and an increased rate of social deprivation, which has had a negative impact on breast cancer screening uptake. [7]

The London borough of Greenwich is equally characterised by multi-ethnic and deprivation communities. Mobility of patients and lack of up to date contact address or telephone numbers have been shown to make many patients 
within Greenwich PCT "hard to reach". The term "hard to reach" has been used in medical and health research in relation to the ability of health services to reach out to certain difficult to contact or difficult to influence sub-groups in a population using existing techniques.[8][9] Thus, increasing breast cancer screening uptake in London is one of the core public health priorities. [10] The primary goal of NHS Greenwich Public Health Breast Screening Project is to increase breast cancer screening uptake within the Greenwich PCT. The first step in achieving this goal is a review of the following literature and finds evidence based intervention that will improve breast cancer screening uptake during current programme.

\section{Literature Review}

As a first step towards developing an effective intervention for increasing breast cancer uptake, we conducted a comprehensive review of literature. The databases searched were Cochrane Database of Systematic Reviews, Medical Literature Online (MEDLINE), British Nursing Index (BNI), Cumulative Index to Nursing and Allied Health Literature (CINAHL), Embase, Google Scholar, Science Direct, Grey Literature. The following major search terms were used: breast cancer, screening, women, intervention; mammography, hard to reach communities and communication messaging technology and short message service (SMS).

The search strategy was comprehensive and included published and unpublished studies. All titles and abstracts retrieved by the electronic search were examined independently by the two authors of this report. The literature search yielded 820 studies, out of which 12 were chosen for critical reading. In the end 8 of the studies were deemed to be the most pertinent to our search aim. The initial criteria included primary research relating to the search terms; literature from 2000 to current day, women and the English language. Women are included in the search terms since the search for intervention is to increase breast cancer screening uptake. The exclusion criteria, on the hand, included non-English language studies, studies and grey literature published before 2000 . The studies which did not meet the inclusion criteria were excluded. The eligibility of retrieved studies was assessed independently by the authors of this report. There were few disagreements, which were resolved through discussion between the two report authors. The reasons for exclusion were also discussed and agreed. The risk of bias tool was applied independently by the two report authors and disagreements resolved through dialogue. The summary of the studies are presented and discussed in the following texts.

A systematic review of nine studies on the effectiveness of interventions aimed at increasing screening uptake for breast, cervical, and colorectal cancers found that the bulk of women invited to screening are likely to have positive intentions towards screening. However, the women require information which should focus on practical issues and allaying concerns to help support that intention, and most importantly, they need reminders to attend screening appointments. [11] In contrast, a study conducted between 1994 and 1996 in four Italian cities where a breast cancer screening programme was active; found that an invitation letter signed by the General Practitioner (GP) brought about 4 to 7 percent higher participation. [12] The study finding was supported by a UK randomised controlled trial, which evaluated the cost-effectiveness of two primary care-based interventions aimed at increasing breast screening uptake for women. The researchers found that letter intervention had 1.5 times better attendance rates than the control group. [13] Similarly, a Swedish randomised controlled trial involving 12,240 participants found that reminder letters increased screening uptake by 9 percent and phone reminders increased uptake by 31.4 percent. The researchers concluded that simple reminders by mail and phone increases women's participation in cancer screening. [14] Another group of scholars carried out a study which evaluated the effectiveness of phone calls in combination with invitation letters and found a 6 percent improvement in uptake when a tailored letter was combined with a phone call. [15] The two later studies, [14] [15] demonstrated that phone calls provide effective reminder, which improves breast screening uptake.

Mobile telephones are becoming an increasingly popular tool for communication between healthcare professionals and patients, one which might offer an inexpensive solution for delivering reminders. Communication technologies such as mobile phones are available to many users, allowing health care professionals to interact with their patients anywhere and anytime. Text messaging via mobile phones, which is now used to remind patients about clinic appointments, has become the most common mode of communication among almost six billion people worldwide. [16] There is strong evidence that client reminders using letter and text (SMS) had increased breast cancer screening uptake. [17] For example, a randomized controlled trial of four SMS reminder interventions found that SMS reminders are the most important tool to achieve optimal response from patients in hard to reach communities. [18] Similarly, a recent single-blind, randomised controlled trial to assess the effectiveness of sending a text message appointment reminder in the London Borough of Hillingdon found that a text message reminder 48 hours before a scheduled breast screening appointment significantly improves uptake. [19] A much earlier study carried out in Western Australia also found that text messaging is an effective medium for communicating health information. [20] [21]

The NHS Greenwich Public Health breast cancer screening project was set up to identify effective intervention aimed at increasing uptake of breast cancer screening among women in the London boroughs of Greenwich and assist in the progress towards achieving national minimum standard of 70 percent. We report below the results obtained from using two different interventions. 


\section{Methods}

Target population: The intervention planned to target a total of 2,004 women from 11 practices who were invited for screening between July and December 2011. The intervention aimed to exclude women whose records showed that they had a diagnosis of colorectal cancer, bowel cancer; palliative care needs or had opted out of the programme.

Of the 2,004 sample of women who were eligible and met the inclusion criteria 1,254 attended the screening in response to the invitation letter and combined letter and text (SMS) reminder; 70 women declined the invitation.

Intervention: Much of research studies about invitation letters for cancer screening focused on the role of GPs in the uptake of cancer screening, GP endorsed letters and phone calls were the main interventions that were evaluated in these studies. [13] [14] [15] [21] Thus, as a mark of good practice, a total of 1,452 women eligible for screening were sent invitation letters as follow:

\section{Letter invitations only intervention}

The letters to the 1,452 eligible women participants were sent through their respective GPs but due to logistical constraints we were unable to use individual practices' letter headings. As a proxy we used NHS Greenwich Goal 2 heading and the letters were signed by the PCT's GP cancer lead. The letter had to be endorsed by the local medical committee (LMC). General Practices (GPs) are unaware that their patients were being sent invitation letters and do not fully engaged in the whole process. However, the GPs were informed of the patient's result if she attends or are sent notification if the women does not attend for screening. Some of the women who attended the mammogram have had a normal result and went back into the 3 year call/recall cycle. Others require an assessment or diagnostic test and will not go back into the three year cycle until their care is completed, or they did not attend the mammogram appointment and will go back into the call/recall system.

\section{Letters and (SMS) Texted reminders intervention}

There are also clear evidence from the studies reviewed earlier that invitation letters with a fellow up SMS reminder are the most effective methods of increasing screening uptake. [11] [13] [14] [15] To increase response from the standard letter invitation as evident in these studies, iPLATO Healthcare Limited was hired and commissioned to send SMS appointment reminders to 552 women participants with valid mobile phone numbers a week before their appointment. The iPLATO campaign was delivered using Patient Care Messaging installed at 11 participating practices [22].

\section{Results}

As noted above, a total of 2,004 women eligible for screening were split into 2 groups of 1,452 and 552 respectively. The former group of women was sent letter only invites and later group of women participants who had valid mobile phone numbers were sent letter combined with an SMS invites. The data in tables below is used to illustrate the significant difference in attendance rates between the two target groups. The names of the practices used in table 1 and 2 have been removed to protect their identity.

Table 1. Letter Invitation Only

\begin{tabular}{|c|c|c|c|}
\hline Surgery & Target Group & Screened & Uptake \\
\hline Practice 1 & 154 & 81 & $53 \%$ \\
\hline Practice 2 & 230 & 148 & $64 \%$ \\
\hline Practice 3 & 140 & 89 & $64 \%$ \\
\hline Practice 4 & 87 & 49 & $56 \%$ \\
\hline Practice 5 & 358 & 226 & $63 \%$ \\
\hline Practice 6 & 31 & 22 & $71 \%$ \\
\hline Practice 7 & 73 & 46 & $63 \%$ \\
\hline Practice 8 & 228 & 133 & $58 \%$ \\
\hline Practice 9 & 70 & 44 & $63 \%$ \\
\hline Practice 10 & 3 & 2 & $67 \%$ \\
\hline Practice 11 & 78 & 38 & $49 \%$ \\
\hline Total 11 & 1,452 & 878 & $60 \%$, \\
\hline
\end{tabular}

The analysis in table 1-4, is iPLATO generated data based on attendance by practice provided by SELBSS, over 6 months period from July 2011 to December 2011. [22] Table1 shows the individual practice's breast cancer screening target who were sent letter only invitation. It also shows the number of women who presented themselves for screening on the basis of the invitation letter and percentage screening uptake. In total, 1,452 women were target and 878 screened, amounting 60 percent screening uptake.

Table 2. Letter Invitation plus SMS reminder

\begin{tabular}{|c|c|c|c|}
\hline Surgery & Target Group & Screened & Uptake \\
\hline Practice 1 & 69 & 45 & $65 \%$ \\
\hline Practice 2 & 52 & 35 & $67 \%$ \\
\hline Practice 3 & 45 & 24 & $53 \%$ \\
\hline Practice 4 & 33 & 18 & $55 \%$ \\
\hline Practice 5 & 133 & 94 & $71 \%$ \\
\hline Practice 6 & 25 & 17 & $68 \%$ \\
\hline Practice 7 & 29 & 23 & $79 \%$ \\
\hline Practice 8 & 94 & 69 & $73 \%$ \\
\hline Practice 9 & 37 & 25 & $68 \%$ \\
\hline Practice 10 & 1 & 1 & $100 \%$ \\
\hline Practice 11 & 34 & 25 & $74 \%$ \\
\hline Total 11 & 552 & 376 & $68 \%$ \\
\hline
\end{tabular}

In table 2, 552 women were sent invitation letter with an SMS reminder; out of which 376 women were screened amounting to 68 percent uptake. Table 3 , details the number of the women who were targeted, those who attended the screening and percentage uptake. It allows clear comparison to be drawn from the number of women in response to the letter only and combined letter and SMS reminder invites.

Of the 2,004 women from 11 practices invited for screening between July and December 2011, 1,254 women attended for screening when they received their invitation, and 70 women contacted by SELBSS decline the invitation. We did not class the women who contacted SELBSS to decline the breast screening after receiving an invitation as Did Not Attend (DNA) because they were offered second time appointment. 
Table 3. Comparing women attending in response letter and letter plus SMS

\begin{tabular}{|c|c|c|c|c|c|}
\hline $\begin{array}{c}\text { Invitation } \\
\text { Method }\end{array}$ & $\begin{array}{c}\text { Total Target } \\
\text { Group }\end{array}$ & $\begin{array}{c}\text { Patients that attended a } \\
\text { Screening }\end{array}$ & $\begin{array}{c}\text { Patients that } \\
\text { attended a } \\
\text { Screening \% }\end{array}$ & $\begin{array}{c}\text { No of patients } \\
\text { who declined }\end{array}$ & $\begin{array}{c}\text { Patients that } \\
\text { Declined } \\
\text { Screening \% }\end{array}$ \\
\hline Letter & 1,452 & 878 & $60 \%$ & 40 & $2.7 \%$ \\
\hline Letter + SMS & 552 & 376 & $68 \%$ & 30 & $5.4 \%$ \\
\hline Total & 2,004 & 1,254 & $62.6 \%$ & 70 & $3.5 \%$ \\
\hline
\end{tabular}

Table 4. Monthly programme screening uptake

\begin{tabular}{|l|c|c|c|c|c|c|c|c|c|}
\hline & April & May & June & July & Aug & Sep & Oct & Nov & Dec \\
\hline 2011 & 58.4 & 57.1 & 55.4 & 57.3 & 58.5 & 62.4 & 60.8 & 57.4 & 66.9 \\
\hline 2010 & 56 & 66 & 67 & 68 & 49.5 & 48.9 & 53.0 & 57.2 & 64.2 \\
\hline
\end{tabular}

Source: SELBSP performance score card

Note: this data needs to be viewed with caution as monthly uptake is dependent on the 3 year rolling plan and should not be used for monthly or yearly comparison as there will be variations.

\section{DNA clinic (second appointment)}

540 women were offered a second timed appointment and referred to as the DNA clinics. They also received a text appointment reminder. Due to a number of inconsistencies in the data such as the inclusion of patients not previously included in first invitation cohort as well as the inclusions of patients whose details had previously been reported as incorrect, it is not possible to provide data on the impact of sending a text reminder to this group. However, data from the clinics show that attendance at the DNA clinics show that 21 percent attended, $(n=118)$ Data from those who received invitation letter combined with SMS reminder and replied to opt out suggest that they were 3 times more likely to notify SELBSS to 'opt out' of screening in comparison to the women who only received letter.

\section{Mobile numbers}

Of the 2004 women invited, only 654 women had mobile numbers recorded on their GP clinical system (33 percent of the women) and 84 percent of these telephone numbers was valid. The proportion of women with recorded telephone numbers was much lower in the DNA group as seen with second timed appointment. There were only 18 percent with a mobile number recorded of which 67 percent were valid. This suggests that we may not have accurate contact details and may account for some of the difficulty in reaching the women within hard to reach communities.

\section{Breast screening uptake percentage point increase}

We compared the uptake in the months of the project (July to Dec 2011) with the uptake in similar months in 2010 and saw improvements. We would have compared the data with the uptake in the same months three years ago and this would have been mainly the same cohort of women but this data was not available.

\section{Quarterly rolling coverage}

This shows the coverage in the same group of practices three years previously. There has been a 2.54 percentage point increase.
Table 5. Quarterly Breast Rolling Coverage data

\begin{tabular}{|c|c|c|}
\hline \multicolumn{3}{|c|}{ Women (age 50 -70 Screened within last 3years) } \\
\hline & & Screening coverage $\%$ \\
\hline Q2 $2009 / 10$ & $01 / 07 / 2009$ to $30 / 09 / 2009$ & 61.03 \\
\hline Q2 $2011 / 12$ & $01 / 07 / 2011$ to $30 / 09 / 2011$ & 63.57 \\
\hline
\end{tabular}

\section{Discussion}

London population is generally characterised by higher rates of mobility, ethnic diversity and an increased rate of social deprivation culminating in many hard to reach women and thus, negative impact on breast cancer screening uptake. [7] Our result shows that letter invitations combined with SMS reminder was most effective intervention in improving breast cancer screening uptake in the Royal Borough of Greenwich PCT, which traditionally had low screening uptake (see table 3 above). An overall 2.54 percent point increase coverage that was achieved may be seen as moderate increase in screening uptake but the impact on health outcome is huge, considering the fact that in UK around 11,600 women died from breast cancer in 2012; amounting to about 32 deaths every day. [2] Also, increased coverage for any breast cancer screening programme is an important measure of the performance of the screening intervention. [25] Thus, the result is significant and may have significant impact on the choice of reminder system for cancer screening in other Primary Care Trusts (PCTs) in London with similar hard to reach communities.

\section{Limitations}

This review authors agree that there was sufficient evidence from good quality studies to support the use of invitation letters and SMS reminders to increase the uptake of breast cancer screening. However, implementation of an effective SMS reminder system requires high mobile phone penetration rates among eligible women. Of the 2,004 women invited, only 654 women had mobile numbers recorded on their GP clinical system (33 percent of the 
women) and 84 percent of these telephone numbers was valid. The proportion of women with recorded telephone numbers was much lower in the DNA group as seen with second timed appointment. There were only 18 percent with a mobile number recorded of which 67 percent were valid. This suggests that we may not have accurate contact details and may account for some of the difficulty in reaching the women. In other words, 33 percent of the women could be considered hard to reach.

In this report, uptake was defined strictly as those who attended their invitation for screening on the scheduled dates. Those who came earlier or later were regarded as non-attendees. A total number of 540 women were offered a second timed appointment; they are referred to as the DNA clinics in this report. The women also received a text appointment reminder. Due to a number of inconsistencies in the data such as the inclusion of patients not previously included in first invitation cohort as well as the inclusions of patients whose details had previously been reported as incorrect, it was not possible to provide data on the impact of sending a text reminder to this group.

\section{Implications for practice and further research}

As SMS can only be as good as the availability of mobile numbers; we suggest that GP practices should work to collect mobile numbers for the next screening round of screening project. More proactive work needs to be done at practice level to identify the women who are due to be screened, and identify what support they require to facilitate attendance and to proactively enter mobile phone numbers for this group. However, the acceptability of a SMS reminder system in breast cancer screening programmes would be worth exploring in future research, especially in the area of privacy. We suggest that future research must address the growing concerns raised about the privacy and confidentiality of the newer technologies in small messaging systems. [26]

SMS is a new communication technology that has been deployed in healthcare to allow professional with mobile phone to send a text message to their patients with mobile phone. The effectiveness of SMS messaging system is mainly in its ability to deliver a text message almost instantly to the patient's mobile phone once it is switched on or read whenever it is convenient to the recipient. We, however, believe that SMS reminder considerably cost less in monetary terms in comparison with other reminder systems, such as mobile telephone calls and email, but this need to be verified by future research.

We demonstrated in this report that invitation letters with SMS reminder increase the uptake of breast cancer screening but no exploration of the effectiveness of different other reminder systems. Thus, we suggest that further studies should be carried out to establish the effectiveness of other reminder systems.

\section{Conclusions}

This report has demonstrated that invitation letter and SMS reminder is effective in improving screening uptake in Greenwich PCT, which has historically had low uptake of breast cancer screening due to many hard to reach communities in the primary care area. Although the conventional letter invitation is effective in improving attendance, SMS provides a more effective reminder system that improves breast cancer screening uptake.

Finally, we recommend further research to address the growing concerns raised about the privacy and confidentiality of the newer Communication technologies. [26] Much as we believe that implementing SMS reminder system cost less in comparison to other reminder systems, we recommend that the cost effectiveness should be verified by future research.

\section{Acknowledgements}

We thank the members of the NHS Greenwich Public Health Breast Cancer Screening Project Team, Bromley PCT screening team and South East Breast Screening Service (SELBSP) team Carmel Hopkins. Finally, we extend our immense gratitude to all the GPs whose invaluable help made this project feasible.

\section{Author Contributions}

Dr. Nike Arowobusoye is the NHS Greenwich Public Health Breast Cancer Screening Project Lead. Dr. Arowobusoye and her team carried out the breast cancer screening programme; performed the statistical analysis and wrote parts of the manuscript. Dr. Vincent Icheku provided the scholarship, wrote parts of the manuscript and carried out the paper editing. Both authors reviewed and approved the final manuscript.

\section{REFERENCES}

[1] Breast Cancer Campaign (2014), Breast Cancer Statistics, http://www.breastcancercampaign.org/about-breast-cancer/b reast-cancer-statistics?gclid=CJPDy9jp07wCFdHLtAodfDg A4A\#breast-cancer-statistics?gclid=CJPDy9jp07wCFdHLtA odfDgA4A\&_suid=139266293167606924757644526207 (Online access, February, 2014)

[2] Cancer Research UK (2014), Breast Cancer, http://publications.cancerresearchuk.org/downloads/Product/ CS_KF_BREAST.pdf

[3] Dey, P., Twelves, E. Woodman, C.B.J. (2013) Breast Cancer, www.birmingham.ac.uk/Documents/collegemds/haps/project s/HCNA/006HCNAchap6.pdf(Online access, February, 2014) 
[4] HSCIC (2014), Breast Screening Programme, England 2012-13: Health and Social Care Information Centre (HSCIC),

http://www.hscic.gov.uk/catalogue/PUB13567(Online access, August, 2014)

[5] NHSBSP (2006) Screening for breast cancer in England past and future: Advisory Committee on Breast Cancer Screening, NHS Breast Screening Programme (NHSBSP), http://www.cancerscreening.nhs.uk/breastscreen/publications /nhsbsp61.pdf (Online access, February, 2014)

[6] Renshaw C, Jack RH, Dixon S, Miller, H., Davies EA. (2010), Estimating attendance for breast cancer screening in ethnic groups in London. BMC Public Health; 10:157.

[7] Cancer Research UK (2007), Response to London Assembly investigation into low uptake of breast cancer screening,http://www.cancerresearchuk.org/prod_consump/g roups/cr_common/@nre/@pol/documents/generalcontent/cr ukmig_1000ast-3300.pdf(Online access, March 2014)

[8] Beder, H.W (1980)Reaching the hard-to-reach adult through effective marketing. New Directions for Continuing Education, 8: 11-26.

[9] Brackertz, N. (2007), Who is hard to reach and why? ISR Working Paper, SISRQ/EL 06.07 Page 1 of 7. http://www.sisr.net/publications/0701brackertz.pdf(Online access, February, 2014)

[10] Zelenyanszki, C. (2009), Maximising Screening Attendance: A Reference Guide, North West London Cancer Network, www.screening.nhs.uk/getdata.php?id=14467(Online access, February, 2014)

[11] Sabatino SA, Lawrence B, Elder R, Mercer SL, Wilson KM, DeVinney B, Melillo S, Carvalho M, Taplin S, Bastani R, Rimer BK, Vernon SW, Melvin CL, Taylor V, Fernandez M, Glanz K, Community Preventive Services Task Force. (2012) Effectiveness of interventions to increase screening for breast, cervical, and colorectal cancers: nine updated systematic reviews for the Guide to Community Preventive Services. American Journal of Preventive Medicine.;43(1):765-786.

[12] Giorgi D, Giordano L, Senore C, Merlino G, Negri R, Cancian M, Lerda M,Segnan N and Del Turco MR (2000). General practitioners and mammographic screening uptake: influence of different modalities of general practitioner participation Working Group, Tumori 86(2):124-9.

[13] Bankhead C, Richards H, Peters J, Sharp J, Hobbs F. Brown J, Roberts L,TydemanC,Redman V, Formby J, Wilson S. and Austoker J. (2001). Improving attendance for breast screening among recent non-attenders: a randomised,controlled trial of two interventions in primary care. Journal of Medical Screening8(2):99-105.

[14] Eaker S, Adami HO Granath F, Wilander E and Sparén P (2004). A largepopulation-based randomised controlled trial to increase attendance at screeningfor cervical cancer. Cancer Epidemiology, Biomarkers \& Prevention 13(3):346-54.

[15] Saywell, R.M Jr, Champion V.L, Skinner C.S, Menon U and Daggy J. (2004). Acost-effectiveness comparison of three tailored interventions to increase mammography screening. Journal of Women's Health 13(8):909-919.

[16] Lunny, C., Taylor, D., Memetovic, J., Wärje,O., Lester, R., Wong, T., Ho, K.,Gilbert, M., and Ogilvie, G., (2014)Short message service (SMS) interventions for the prevention and treatment of sexually transmitted infections: a systematic review protocol,

http://www.systematicreviewsjournal.com/content/3/1/7(Onl ine access, March 2014)

[17] Centres for Disease Control and Prevention (2012), Effectiveness of interventions to increase cancer screening, http://www.cdc.gov/cancer/breast/what_cdc_is_doing/screen ing int.htm(Online access, March 2014)

[18] Pop-Eleches C, Thirumurthy H, Habyarimana JP, Zivin JG, Goldstein MP, de Walque D, MacKeen L, Haberer J, Kimaiyo S, Sidle J, Ngare D, Bangsberg DR: (2011), Mobile phone technologies improve adherence to antiretroviral treatment in a resource-limited setting: a randomized controlled trial of text message reminders, AIDS (Hagerstown), 25:825-834.

[19] Kerrison, R., Shukla, H., Cunningham, D.,Oyebode, O. and Friedman, E., (2013) Are text message reminders an effective intervention to improve uptake of breast screening? A randomised controlled trial, The Lancet, Volume, Page S9, 29 November, doi:10.1016/S0140-6736(13)62434-4

[20] Wilkin. A. and Mak ,D.B. (2007), Sending out an SMS: an impact and outcome evaluation of the Western Australian Department of Health's 2005 Chlamydia campaign, Health Promotion Journal of Australia; 18:113-20

[21] Threlfall, A and Fazil, A (2009), Approaches to increase attendance at Breast and Cervical Cancer Screening in Greater Manchester, GM PUBLIC HEALTH PRACTICE UNIT, www.gmpublichealthpracticeunit.nhs.uk(Online access, February, 2014)

[22] iPLATO (2012) NHS Greenwich mHealth Patient Engagement Project Evaluation: Breast Screening, iPLATO Healthcare Limited

[23] Royal Borough of Greenwich (2014), Population data, http://www.royalgreenwich.gov.uk/info/200088/statistics an d_census_information/114/population_data(Online access, March 2014)

[24] NHSBSP (2011), Breast Screening Programme: Annual Review

2011,http://www.cancerscreening.nhs.uk/breastscreen/public ations/nhsbsp-annualreview2011.pdf(Online access, Februar $\mathrm{y}, 2014)$

[25] Sabates R and Feinstein L. (2006). The role of education in the uptake of preventative health care: the case of cervical screening in Britain. Social Science \& Medicine 62(12):2998-3011.

[26] Norwell, N. (2003), Text messaging raises medico legal issues (letter). British Medical Journal 326(7399):1148 